\title{
Intracellular anti-leishmanial effect of Spergulin-A, a triterpenoid saponin of Glinus oppositifolius
}

This article was published in the following Dove Press journal:

Infection and Drug Resistance

\author{
Saswati Banerjee $\mathbb{D}^{1, *}$ \\ Niladri Mukherjee ${ }^{\text {,** }}$ \\ Rahul L Gajbhiye ${ }^{2}$ \\ Snehasis Mishra' \\ Parasuraman Jaisankar (D) ${ }^{2}$ \\ Sriparna Datta ${ }^{3}$ \\ Krishna Das Saha' \\ 'Cancer Biology and Inflammatory \\ Disorder Division, CSIR-Indian Institute \\ of Chemical Biology, Kolkata 700032, \\ India; ${ }^{2}$ Organic and Medicinal Chemistry \\ Division, CSIR-Indian Institute of \\ Chemical Biology, Kolkata 700032, India; \\ ${ }^{3}$ Department of Chemical Technology, \\ University of Calcutta, Kolkata 700009 \\ India
}

*These authors contributed equally to this work
Correspondence: Krishna Das Saha Cancer Biology and Inflammatory Disorder Division, CSIR-Indian Institute of Chemical Biology, 4 Raja S. C. Mullick Road, Kolkata 700032, India

Tel +9l 03324995810

Email krishna@iicb.res.in
Background: Many of present chemotherapeutics are inadequate and also resistant against visceral leishmaniasis (VL), an immunosuppressive ailment caused by Leishmania donovani. Despite the interest in plant-based drug development, no antileishmanial drugs from plant source are currently available. Glinus oppositifolius had been reported in favor of being immune modulators along with other traditional uses. Novel anti-VL therapies can rely on host immune-modulation with associated leishmanicidal action.

Objective: Discovery of novel plant-based antileishmanial compound from G. oppositifolius having permissible side effects.

Methods: With this rationale, an $\mathrm{n}-\mathrm{BuOH}$ fraction of the methanolic extract of the plant and obtained triterpenoid saponin Spergulin- $A$ were evaluated against acellular and intracellular $L$. donovani. Immunostimulatory activity of them was confirmed by elevated TNF- $\alpha$ and extracellular NO production from treated MФs and was found nontoxic to the host cells. Identification and structure confirmation for isolated Spergulin-A was performed by ESI-MS, ${ }^{13} \mathrm{C}$, and ${ }^{1} \mathrm{H}$ NMR.

Results: Spergulin-A was found ineffective against the acellular forms while, against the intracellular parasites at $30 \mu \mathrm{g} / \mathrm{mL}$, the reduction was $92.6 \%$ after 72 hrs. Spergulin-A enhanced ROS and nitric oxide (NO) release and changes in Gp91-phox, i-NOS, and pro and anti-inflammatory cytokines elaborated its intracellular anti-leishmanial activity.

Conclusion: The results supported that $G$. oppositifolius and Spergulin-A can potentiate new lead molecules for the development of alternative drugs against VL.

Keywords: visceral leishmaniasis, Glinus oppositifolius, spergulin-A, macrophage, immunostimulation, anti-amastigote

\section{Introduction}

Visceral leishmaniasis (VL) considered as the most severe form of leishmaniasis caused by Leishmania donovani and untreated patients nearly always die. ${ }^{1}$ Leishmaniasis is endemic in nearly 100 countries with approximately 350 million people are at risk with an estimated yearly incidence of 500,000 cases and almost 70,000 deaths. Leishmaniasis is liable for the ninth most substantial infectious diseases burden, however, is mostly disregarded among tropical disease priorities. ${ }^{2}$ Sodium antimony gluconate, Miltefosine, Pentamidine, and Amphotericin B are the primary therapeutics though associated with toxicity or resistance. ${ }^{3}$

Pathogen recognition by neutrophils, macrophages, dendritic cells, and natural killer cells activates intracellular signaling pathways leading into inflammatory responses like inflammasome activation and IL-1 $\beta$ production, which is not the case for leishmanial infection. ${ }^{4} L$. donovani infection is characterized by the 
parasite-induced active subversion of the host immune system and also immune deviation which additively favors infection establishment. ${ }^{5}$ Additionally, Leishmania prevents inflammatory response by the impaired release of different pro-inflammatory cytokines (IL-1, TNF- $\alpha$, IL-12) and enhanced releases of immunosuppressive signaling molecules, such as arachidonic acid metabolites and the cytokines TGF- $\beta$ and IL- $10 .^{6}$ Involvement of co-stimulatory molecule B7-CTLA-4 is associated with increased TGF- $\beta$ production in VL with increased apoptosis of $\mathrm{CD}^{+} \mathrm{T}$ cells and decreased macrophage apoptosis. ${ }^{7}$ Leishmanial infection also undermines a generation of microbicidal macrophage nitric oxide (NO) and reactive oxygen species (ROS) with the hindrance of antigenic peptide display to T cells, and permeation of IL-10 producing $\mathrm{T}$ regulatory cells. ${ }^{8}$ In recent years, increased instances of VL have been reported in connection with immune-suppressed AIDS patients. ${ }^{8}$

Discovery of novel compounds which intercedes host immune-modulation associated with leishmanicidal function having permissible side effects is a precise research objective. $^{9,10}$ It is also of vital importance that the drug required for parasite elimination in immune-stimulated cells was significantly less than the immune-suppressed ones. ${ }^{11}$

The anti-parasitic effectiveness of plant extracts majorly relies upon secondary metabolites of diverse chemical groups including alkaloids, polyphenol, flavonoids, terpenoids, phenylpropanoids, etc. ${ }^{12}$ For isolation and characterization of a herbal extract or an active compound, different research strategies can be employed mainly in the extraction steps. However, bioactivity-guided fractionation considered as simple, rapid, cost-effective and reproducible. ${ }^{1}$ For obtaining a potent anti-leishmanial agent with immunemodulation, different studies were conducted with compounds like aslicarin A, niranthrin, skimmianine, quassin, tannins, linalool, etc., nevertheless with varying degree of effectiveness and satisfaction. ${ }^{8}$

Aerial parts of Glinus oppositifolius (Family Mollugin aceae) are used for treating abdominal pain and jaundice, while decoction is used against malaria. ${ }^{13}$ Plants of this genus were previously documented for the presence of triterpenoid saponins, ${ }^{14}$ and isolated pectin polysaccharides are antiprotozoal $^{15}$ and immunomodulators. ${ }^{14} G$. oppositifolius is indicated for wound healing and used in traditional medicine for treating diarrhea, joint pains, inflammations, intestinal parasites, fever, boils and skin disorders. ${ }^{16}$ Some triterpenoid saponins, 3-O-( $\beta$-D-xylopyranosyl)-spergulagenin-A, Spergulacin, Spergulacin-A
Spergulin-A, and Spergulin-B had been isolated from G. oppositifolius. ${ }^{17}$ Application of plant-based immunomodulators is smart as they mediate their effectiveness by enhancing the inherent host-derived protective machinery without the involvement of specific microbicidal agents, namely antibiotics. ${ }^{13}$

Most of the available antimalarial drugs are plantderived; regrettably, there is no anti-leishmanial drug present which is of plant origin. The recent efforts to achieve this goal also were restricted against the promastigotes. ${ }^{18}$ In the present work, an attempt has been taken to evaluate the intracellular anti-leishmanial activity of this plant and its bioactive component, Spergulin-A emphasizing on the immunostimulatory activity.

\section{Materials and methods \\ Chemicals and reagents}

Cell culture media, serum, antibiotics, HEPES (Gibco, USA), CFSE, DAPI (Invitrogen, USA), MTT, Miltefosine, DMSO (Sigma Chemical Co. USA), cytokine Assay kit (Thermo Scientific, USA), DAF-2 DA, nitric oxide assay kit, DCFDA (Calbiochem, USA) and all other chemicals were of the highest grade commercially available. Primary and secondary antibodies were obtained from Santa Cruz Biotechnology (USA) or Cell Signaling Technologies (USA).

\section{Isolation of methanolic fractions from $G$. oppositifolius}

The aerial parts of G. oppositifolius were shade dried $(1 \mathrm{~kg})$ and were first defatted using petroleum ether $(60-$ $80^{\circ} \mathrm{C}, 3.5 \mathrm{~L} \times 3$ ) at room temperature for $48 \mathrm{hrs}$. The marc was then subjected to extraction using $\mathrm{MeOH}$ $(3.5 \mathrm{~L} \times 3)$ at room temperature for $48 \mathrm{hrs}$. The extract was then filtered and $\mathrm{MeOH}$ was evaporated under reduced pressure and finally was lyophilized to obtain the crude $\mathrm{MeOH}$ extract (13 g). A part (10 g) of ME was then suspended in milli-Q water and partitioned sequentially with EtOAc and n-BuOH. Each fraction was evaporated under vacuum and lyophilized to yield the EtOAc fraction (EAF; $3.6 \mathrm{~g}$ ), $\mathrm{n}-\mathrm{BuOH}$ fraction $(\mathrm{NBF} ; 4.1 \mathrm{~g})$ and aqueous fraction (AF; $2.3 \mathrm{~g})$. All the fractions were stored at $4{ }^{\circ} \mathrm{C}$ till further use.

Among these four fractions, $\mathrm{n}-\mathrm{BuOH}$ showed promising anti-leishmanial activity. Around $4 \mathrm{~g}$ of NBF was subjected to column chromatography of Diaion HP 20 $(100 \mathrm{~g})$ and the column washed with water followed by $30 \%, 40 \%, 60 \%, 80 \%$, and $100 \%$ of $\mathrm{MeOH}$ to obtain a 
total of six fractions. Fractions eluted with $50 \% \mathrm{MeOH}$ showed similar spots on TLC and were mixed and then rechromatographed on Dianion HP 20 column to furnish $7 \mathrm{mg}$ of Spergulin-A. The compound isolation procedures were performed as followed by Kumar et al. ${ }^{19}$

\section{Isolation and characterization of Spergulin-A}

ESI Mass spectra were recorded on an Agilent 6545 Q-TOF mass spectrometer System. ${ }^{1} \mathrm{H}$ and ${ }^{13} \mathrm{C}$ NMR were recorded on a Bruker Ultrashield NMR (600 MHz) in pyridine-d5 with TMS as an internal standard. Diaion HP 20 was used for column chromatography; silica gel (60 F254) was used for TLC and spots were visualized by spraying with Lieberman-Burchard reagent followed by heating.

\section{Parasite culture and maintenance}

Leishmania donovani strain Ag83 [MHOM/IN/1983/AG83] was used for the experiments. Promastigotes obtained from transforming amastigote from infected BALB/c mice spleen were maintained in M199 supplemented with $10 \% \mathrm{FBS}, \mathrm{pH}$ 7.4, $100 \mathrm{U} / \mathrm{mL}$ penicillin G-sodium, $100 \mu \mathrm{g} / \mathrm{mL}$ streptomycin sulfate, $25 \mathrm{mM}$ HEPES at $22{ }^{\circ} \mathrm{C}$. For infection, mice were inoculated with $2 \times 10^{7}$ promastigotes in $0.5 \mathrm{~mL}$ of saline. Axenic amastigote from late logarithmic phase cultures of Ag83 promastigotes were prepared as described by Saar et al. ${ }^{20}$ Pathogen- and animal-related work has been carried out within prior permission from Institutional Biosafety Committee, CSIR-Indian Institute of Chemical Biology (CSIR IICB/IBSC/CERT-32/18-19) and CSIRIICB-Animal Ethics Committee (IICB/AEC/Meeting/Oct/ 2017) according to the Committee for the Purpose of Control And Supervision of Experiments on Animals (CPCSEA) guidelines, respectively.

\section{Macrophage culture, parasite infection, and treatment}

RAW 264.7 MФ cell line was obtained from the ATCC and maintained in complete RPMI 1640 (10\% FBS, $100 \mu \mathrm{g} / \mathrm{mL}$ streptomycin sulfate, $100 \mathrm{U} / \mathrm{mL}$ penicillin $\mathrm{G}$ sodium, $0.2 \%$ sodium bicarbonate, $25 \mathrm{mM}$ HEPES) in a humidified atmosphere and $5 \% \mathrm{CO}_{2}$ at $37^{\circ} \mathrm{C}$.

Infection of MФs with $L$. donovani promastigotes was performed in a ratio of 1:10 (MФ: parasite) for $4 \mathrm{hrs}$ then washed twice with media. Normal and parasitized macrophages were treated with G. oppositifolius fractions or Spergulin-A at required concentrations up to $72 \mathrm{hrs}$.
Infection was measured by counting the intracellular parasites and expressed as parasite count/20 МФs. Miltefosine served as positive anti-leishmanial reference.

\section{ELISA assay}

Cell-free supernatants from MФs $\left(1 \times 10^{5}\right.$ cells/well $)$ were collected, and the concentration of pro-inflammatory TNF- $\alpha$, IL-6, IL-12, IL-12 $\beta$, IL-1 $\beta$ and anti-inflammatory IL-10 and TGF- $\beta$ cytokines was estimated by sandwich ELISA, using a commercially available assay kit. ${ }^{21}$

\section{MTT assay}

$20 \mu \mathrm{L}$ of MTT ( $5 \mathrm{mg} / \mathrm{mL}$ in PBS) was added to each well of the control and treated МФs $\left(4 \times 10^{3}\right)$ and $5 \times 10^{3}$ parasites (promastigote and axenic amastigote) in a 96 well plate and incubated for $4 \mathrm{hrs}$ at $37^{\circ} \mathrm{C}$ and the formazan crystals were dissolved in $150 \mu \mathrm{L}$ of DMSO. Absorption was measured at $595 \mathrm{~nm}$ by an ELISA reader. ${ }^{22}$

\section{Measurement of extracellular NO}

The collected supernatants from control, infected and treated МФs were incubated with equal volumes of Griess reagent, NED ( $0.1 \%$ in distilled water) and sulphanilamide $\left(1 \%\right.$ in $\left.5 \% \mathrm{H}_{3} \mathrm{PO}_{4}\right)$ at room temperature for 10 mins. The absorbance was measured at $540 \mathrm{~nm}$ on a microplate reader. NO concentration was determined using a dilution of sodium nitrite as the standard. ${ }^{21}$

\section{FACS and confocal microscopy with CFSE-tagged $L$. donovani}

MФs were parasitized with CFSE-tagged $\left(25 \mu \mathrm{M} / 1 \times 10^{6}\right.$ promastigote in $1 \mathrm{~mL}$ media for $30 \mathrm{mins}$ ) promastigotes followed by Spergulin-A $(10,20,30 \mu \mathrm{g} / \mathrm{mL})$ treatment for $24 \mathrm{hrs}$.

For confocal microscopy, MФs $\left(1 \times 10^{5} /\right.$ glass coverslips $)$ after infection and treatment, washed twice with PBS, fixed in chilled $70 \%$ ethanol and nuclei were stained with DAPI and observed under Olympus Fluoview FV10i confocal microscope with $60 \times$ objective lens. For FACS, MФs $\left(1 \times 10^{5} /\right.$ well in a six-well plate) after infection and treatment, washed twice with PBS then harvested by scraping and resuspended in $400 \mu \mathrm{L}$ PBS and analyzed by BD FACS LSR Fortessa with excitation at $494 \mathrm{~nm}$ and emission at $518 \mathrm{~nm}$.

\section{FACS analyses of intracellular ROS and NO}

The level of intracellular ROS was determined based on the change in fluorescence of H2DCFDA. DAF-2 DA was used 
for detecting intracellular NO. ${ }^{3}$ Briefly, after infection and treatment, MФs were scrapped and incubated in PBS containing DAF-2DA $(7.0 \mu \mathrm{M})$ at $37^{\circ} \mathrm{C}$ for 30 mins or $20 \mu \mathrm{M}$ DCF-DA at $37^{\circ} \mathrm{C}$ for 15 mins and then analyzed by BD FACS LSR Fortessa with excitation at $480 \mathrm{~nm}$ and emission at $515 \mathrm{~nm}$ for both.

\section{Western blot analysis}

$40 \mu \mathrm{g}$ of proteins harvested from MФs were electrophoretically separated in SDS-PAGE and transferred to PVDF membrane, blocked with BSA and incubated with respective primary antibodies overnight. The membranes were then incubated with HRP conjugated secondary antibodies, and immunoreactive bands were visualized by adding proper substrates. $\beta$-Actin was used as loading controls. ${ }^{23}$

\section{Statistical analysis}

All values were expressed as mean \pm SEM obtained from at least three replicate experiments. Statistical significance and differences among groups were assessed with one-way ANOVA followed by Dunnett's test. $P$-values $\leq 0.05$ (*) or $\leq 0.01(* *)$ were considered as indicative of significance.

\section{Results}

\section{Immunostimulatory effect of methanolic extract of $G$. oppositifolius}

Of the aqueous, ethyl acetate and n-BuOH (50:50) fractions of $G$. oppositifolius methanolic extract, only the n-BuOH fraction $(50 \mu \mathrm{g} / \mathrm{mL})$ showed a considerable increase in TNF- $\alpha$ and extracellular NO production (Figure S1) from the treated (24 hrs) MФs. The six sub-fractions $(50 \mu \mathrm{g} / \mathrm{mL})$ of the $\mathrm{n}-\mathrm{BuOH}$ fraction were also checked for the same parameters (Figure 1A and B), and highest augmentation was noticed in fraction 4 for being a worthy immunostimulatory agent and the lead fraction (Figure 2A).

\section{Dose-dependent immunostimulatory effect of the lead fraction}

A dose-dependent increase in TNF- $\alpha$ production was monitored in treated (24 hrs) MФs in two sets (Figure 2B). In first set the lead fraction was applied at the doses of 10, 20, 40 and $80 \mu \mathrm{g} / \mathrm{mL}$ (Figure $2 \mathrm{~B}$ ) and in the second set at the doses of 20,30, 40 and $50 \mu \mathrm{g} / \mathrm{mL}$ and most increments were noticed at $30 \mu \mathrm{g} / \mathrm{mL}$ (Figure $2 \mathrm{~B}$ ) and selected as the significant dose for this study.

\section{Assessment of macrophage survival and extracellular NO release}

Survival of the MФs after exposing them to increasing concentrations $(10,20,30,40$ and $50 \mu \mathrm{g} / \mathrm{mL})$ of the lead fraction for 24, 48 and $72 \mathrm{hrs}$ was monitored by MTT assay (Figure 2C). The lead fraction was found safe for this dose range, and survival was about $81.45 \%$ even at 50 $\mu \mathrm{g} / \mathrm{mL}$ after $24 \mathrm{hrs}$. And, at $30 \mu \mathrm{g} / \mathrm{mL}$ survival of exposed MФs was found to be $93.22 \%, 89.87 \%$ and $87.88 \%$, respectively, after 24, 48 and 72 hrs. Most increment (5fold) in extracellular NO was noticed for $30 \mu \mathrm{g} / \mathrm{mL}$ of the lead fraction (Figure 2D). The increase was also significant for most of the doses.

\section{Identification and characterization of Spergulin-A}

Among those six n-BuOH bioactive sub-fractions, fraction 4 has shown the most significant upliftment in TNF- $\alpha$ and extracellular NO production. After purification of this
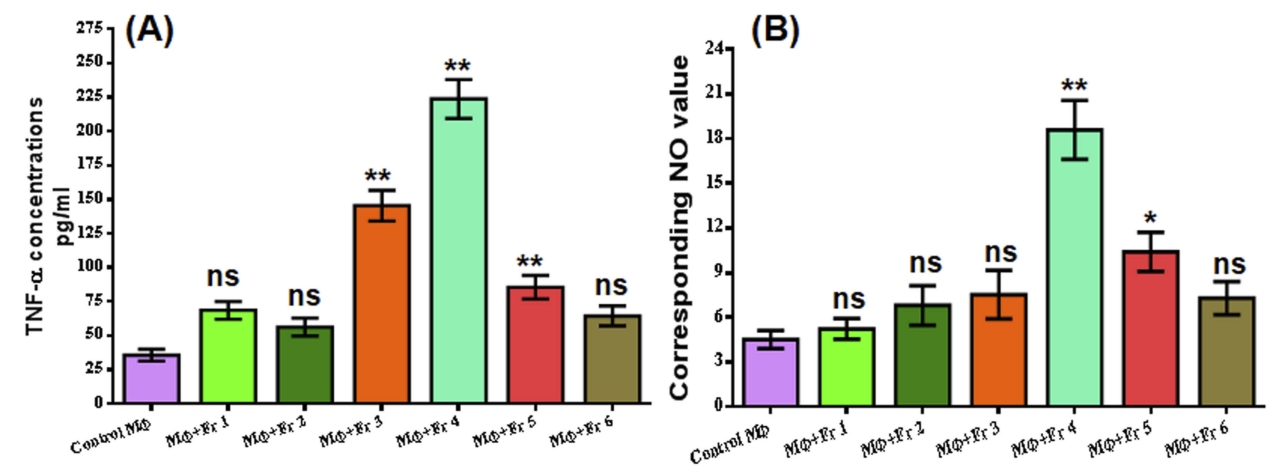

Figure I Evaluation of immunostimulation by subfractions of $n-B u O H$ fraction of $G$. oppositifolius $\mathrm{MeOH}$ extract. (A) The subfractions $(50 \mu \mathrm{g} / \mathrm{mL})$ were checked for altered TNF- $\alpha$ production after $24 \mathrm{hrs}$ treatment of RAW 264.7 MФs from the culture supernatant. (B) Extracellular NO production was monitored in the culture supernatant of treated (six subfractions) and control after $24 \mathrm{hrs}$ by Griess reagent. All values are expressed as mean \pm SEM from triplicate assays from three independent experiments $(P$ values $\leq 0.05\left(^{*}\right)$ or $\leq 0.0$ l (**) vs control). 


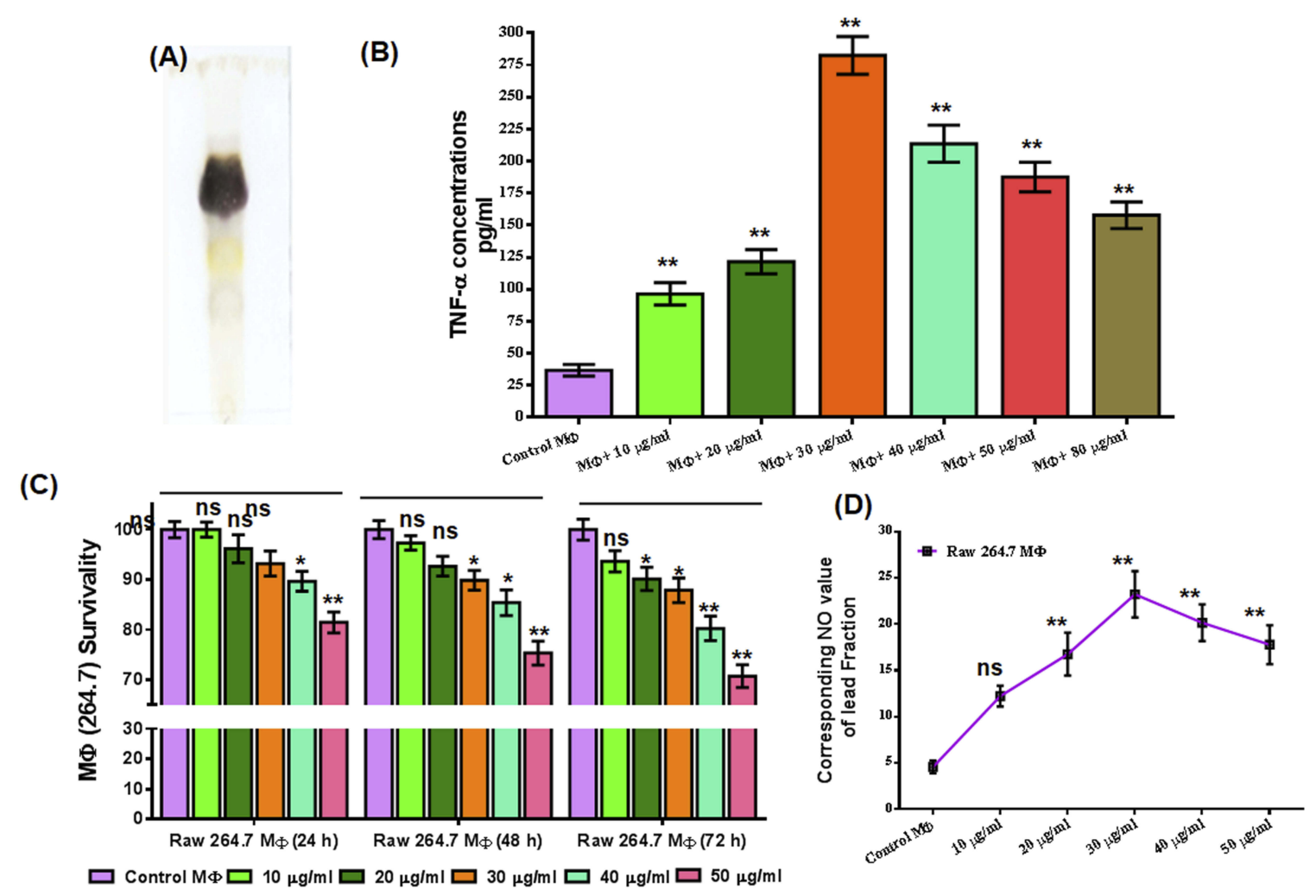

Figure 2 Dose-dependent evaluation of the immunostimulatory effect of the $n-B u O H$ lead fraction and impact on RAW 264.7 MФ survival. (A) TLC profile of $n$-BuOH lead fraction. (B) The dose-dependent release of TNF- $\alpha$ was monitored in treated ( $24 \mathrm{hrs})$ RAW $264.7 \mathrm{M \Phi s}$, and highest increment was found in $30 \mu \mathrm{g} / \mathrm{mL}$. (C) Survival of RAW

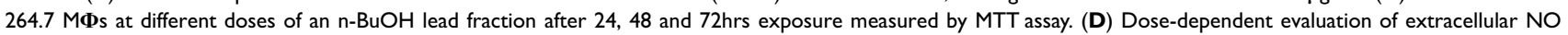
production was monitored in the culture supernatant of $24 \mathrm{hrs}$ treated RAW 264.7 MФs by Griess reagent. All values are denoted as mean \pm SEM from triplicate assays from three independent experiments (P-values $\leq 0.05(*)$ or $\leq 0.01(* *)$ vs control).

fraction by using column chromatography, a white amorphous compound was obtained. Molecular formula C35H58O11S (Figure 3A) was assigned from the ESIMS (Figure S2). Structural elucidation of this compound was achieved by critical analysis of the ${ }^{1} \mathrm{H}$ NMR, $13 \mathrm{C}$ NMR and 13C NMR DEPT results (Supplementary results and Figures S3-S6). All the spectral data of this compound were found to be in complete agreement with reported ones and structure was then confirmed as Spergulin-A. ${ }^{24}$

\section{Assessment of anti-leishmanial activity of Spergulin-A}

Effect on promastigote and axenic form of $L$. donovani Anti-leishmanial effect of Spergulin-A (10, 20, 30, 50, 100 $\mu \mathrm{g} / \mathrm{mL}$ ) was first evaluated by MTT assay against promastigote and axenic amastigote, the acellular forms (Figure 3B) at $24 \mathrm{hrs}$ interval up to $72 \mathrm{hrs}$. Viability was $87.6 \%$ and $77.8 \%$, respectively, for promastigote and axenic forms even at $100 \mu \mathrm{g} / \mathrm{mL}$ after $24 \mathrm{hrs}$ and $74.79 \%$ and $73.55 \%$ even after $72 \mathrm{hrs}$ at the exposed dose of $100 \mu \mathrm{g} / \mathrm{mL}$. At the lower doses $(10,20$ and $30 \mu \mathrm{g} / \mathrm{mL})$ the viability reduction was found to be non-significant (Figure 3B).

After that, the effect of Spergulin-A was evaluated against the $М \Phi$ internalized parasites (Figure 3C). A significant reduction of intracellular L. donovani was monitored in 10 $\mu \mathrm{g} / \mathrm{mL}$ of Spergulin-A exposure and parasite count further reduced with the increment of doses (Figure 3C). However, above $30 \mu \mathrm{g} / \mathrm{mL}$ МФ internalized the anti-leishmanial effect of Spergulin-A had reached a plateau, and thus further experiments were mostly conducted with $30 \mu \mathrm{g} / \mathrm{mL}$.

\section{Time-dependent intracellular leishmanicidal effect}

Efficacy of Spergulin-A $(30 \mu \mathrm{g} / \mathrm{mL})$ against the intracellular parasites was evaluated at every $24 \mathrm{hrs}$ interval up to $72 \mathrm{hrs}$ (Figure 3D). Inside the infected MФs parasite count increased significantly. The treated MФs exhibited significantly reduced numbers of parasites from the initial infection as well as the corresponding observation point of infected macrophages (Figure 3D). The parasite reduction at $72 \mathrm{hrs}$ was $86.2 \%$ less than the initial point of infection and $92.6 \%$ 


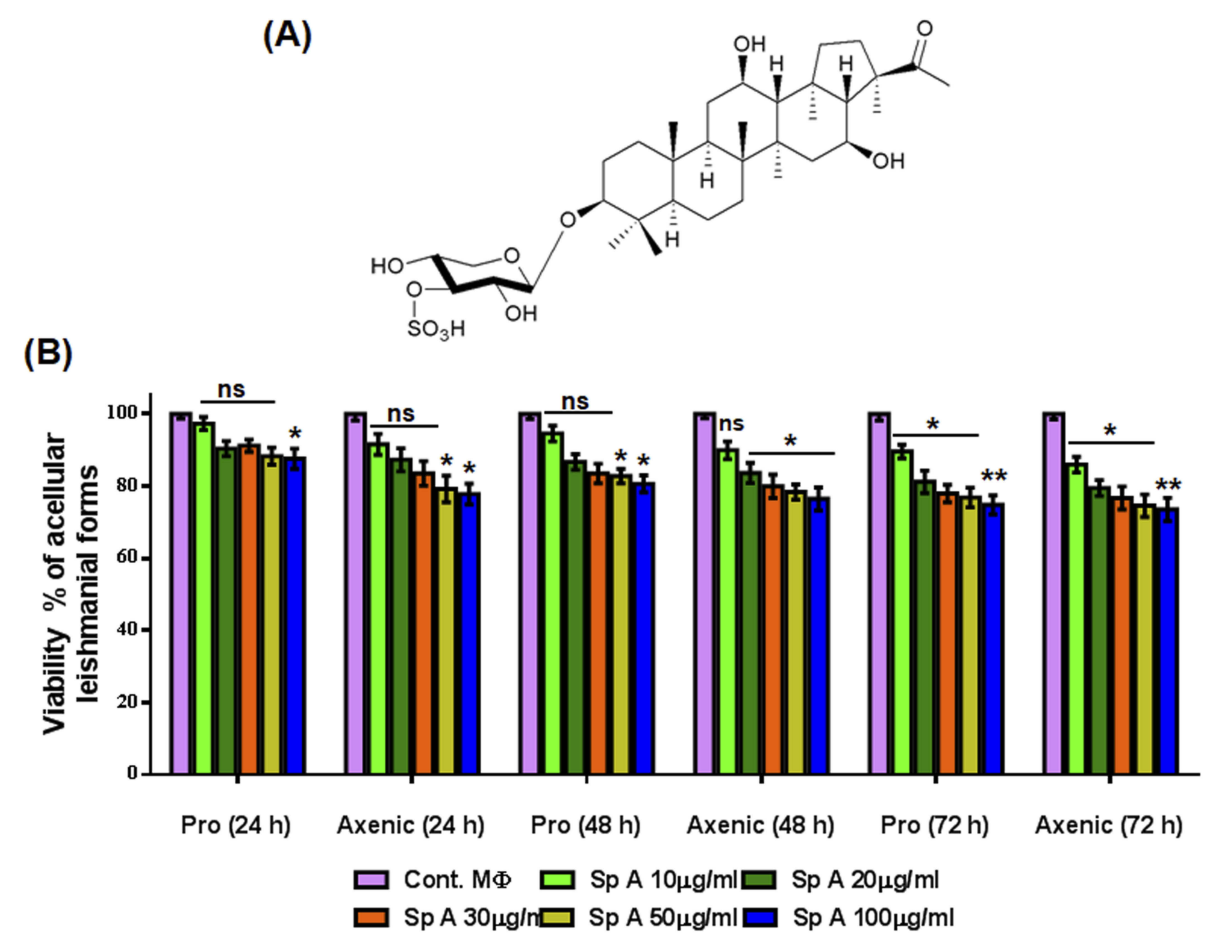

(C)

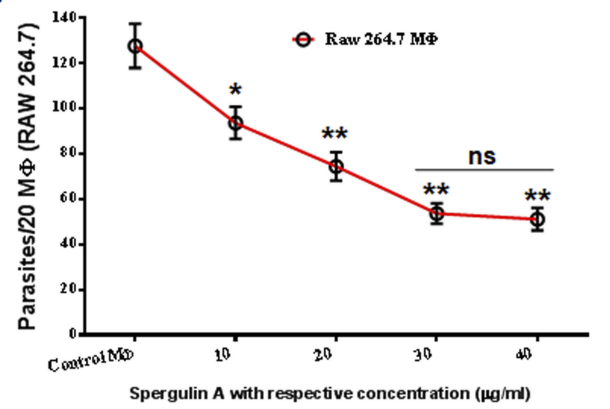

(D)

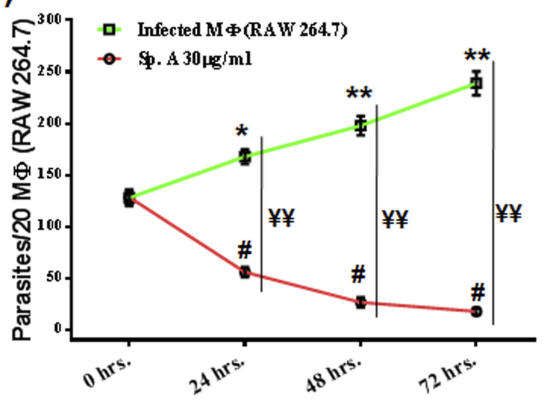

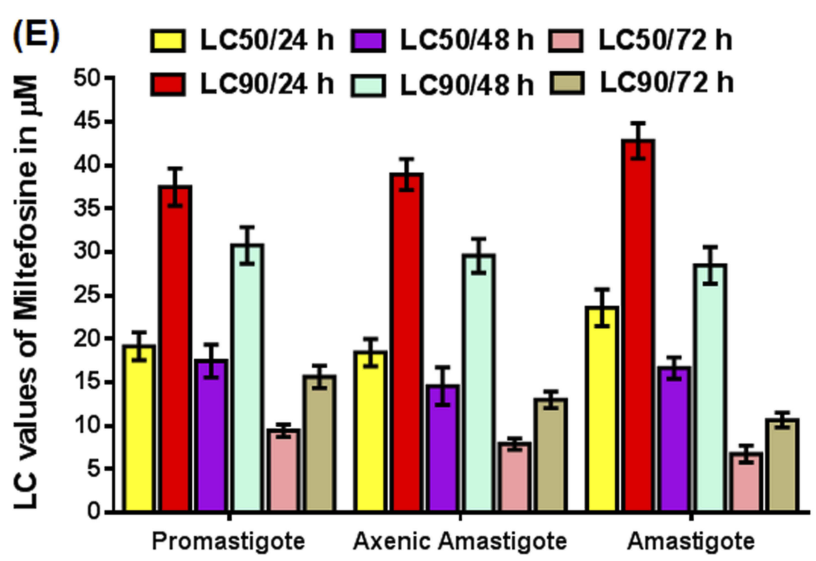

Figure 3 Anti-leishmanial activity of Spergulin-A. (A) Structure of the triterpenoid saponins Spergulin-A. (B) Dose-dependent effects of Spergulin-A against acellular stages, namely the promastigotes and axenic amastigote of Leishmania donovani after 24, 48 and 72 hrs interval. (C) Dose-dependent effect of Spergulin-A against the intracellular amastigote of $L$. donovani after $24 \mathrm{hrs}$ of treatment and expressed as number of parasites/20 MФs. (D) $24 \mathrm{hrs}$ time lapse evaluation of anti amastigote effect of Spergulin-A at $30 \mu \mathrm{g} / \mathrm{mL}$ for $72 \mathrm{hrs}$. (E) Miltefosine $L_{50}$ and $L C_{90}$ values against promastigote, axenic amastigote and intracellular amastigote forms of $L$. donovani at 24,48 and 72 hrs time lapse. All values are expressed as mean \pm SEM from triplicate assays from three independent experiments $(P$-values $\leq 0.05(*)$ or $\leq 0.0$ I (**) vs control). ${ }^{\#}$ Statistical significance of treated macrophages with different time lapses with respect to 0 hrs. ${ }^{\sharp}$ Statistical significance of the differences between the infected macrophages and treated macrophages at the same time. 
less than the $72 \mathrm{hrs}$ count of infected MФs. Miltefosine was used in parallel as a positive reference anti-leishmanial compound and $\mathrm{LC}_{50}$ and $\mathrm{LC}_{90}$ values of it at $24 \mathrm{hrs}$ time interval for $72 \mathrm{hrs}$ against these three forms were expressed as histogram (Figure $3 \mathrm{E}$ ). $\mathrm{LC}_{50}$ values of Spergulin-A against amastigote stage of $L$. donovani was found to be $15.15,9.32$ and $6.22 \mu \mathrm{g} / \mathrm{mL}$ after 24,48 and $72 \mathrm{hrs}$, respectively, as compared to Miltefosine $\mathrm{LC}_{50}$ doses of $23.59,16.64$ and $6.73 \mu \mathrm{g} / \mathrm{mL}$ after the same time intervals of 24,48 and $72 \mathrm{hrs}$.

\section{Dose-dependent quantitative and qualitative anti-leishmanial effect}

After infecting the MФs with CFSE-tagged promastigotes and treatment with Spergulin-A (10, 20 and $30 \mu \mathrm{g} / \mathrm{mL}, 24 \mathrm{hrs})$, the cells were evaluated by FACS in FITC filter (Figure 4A.i-v). Highest intensity was noticed in the infected panels (Figure 4A.ii) and with the increment of Spergulin-A doses, the intensity gradually reduces which is reciprocal to the reduced parasite count (Figure 4A.iii-v). Interestingly, no
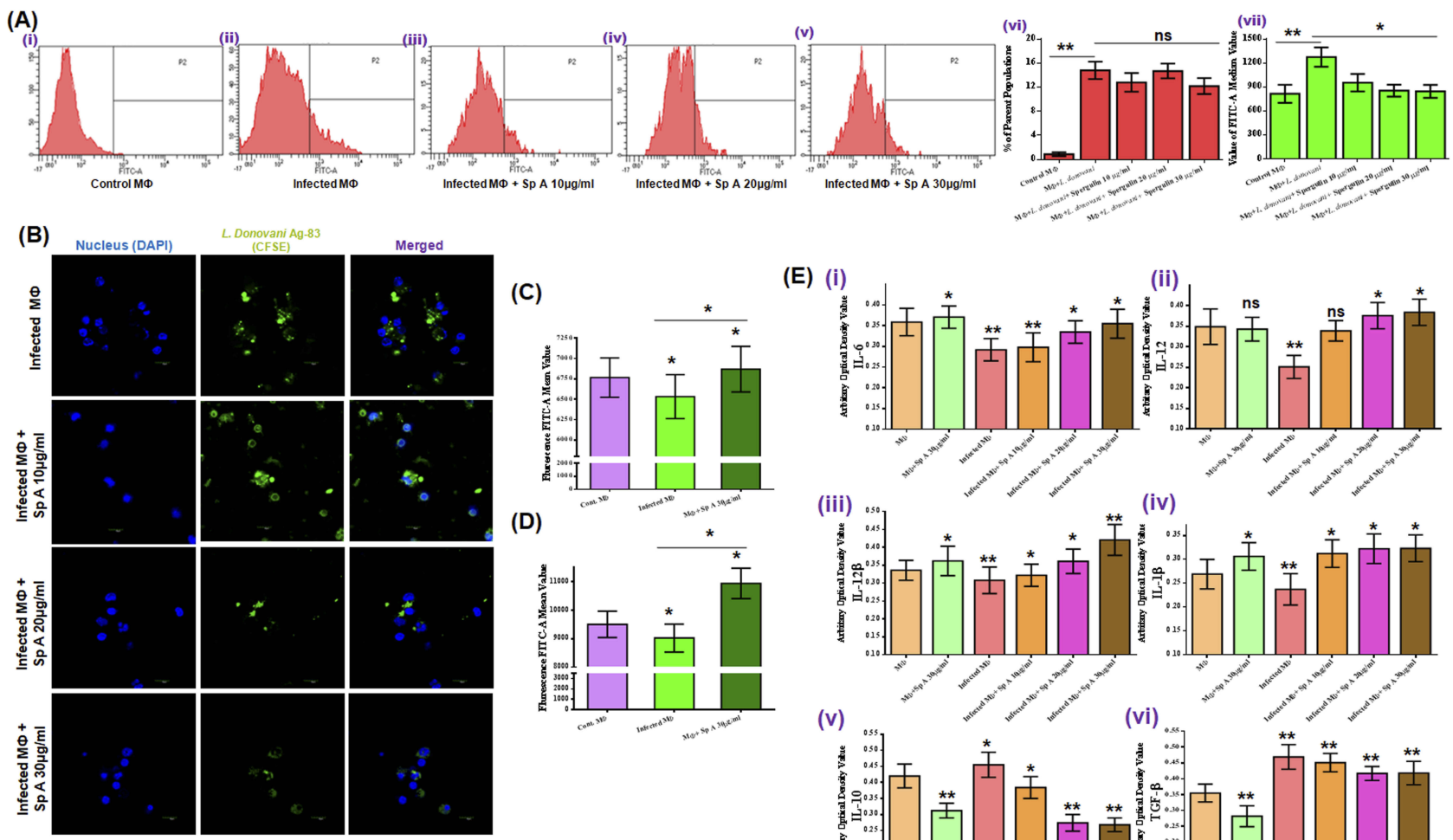

(C)

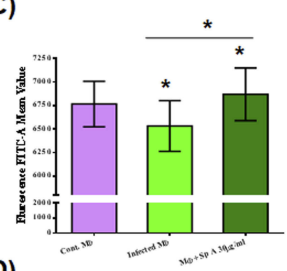

(D)

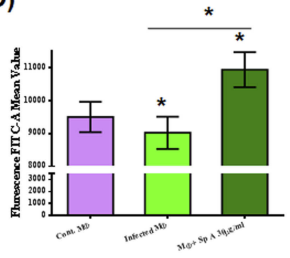

(E) (i)

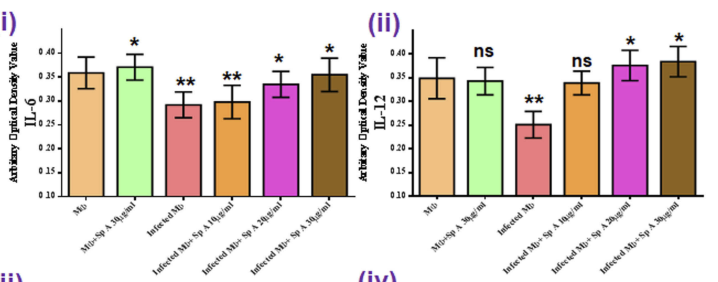

(iv)

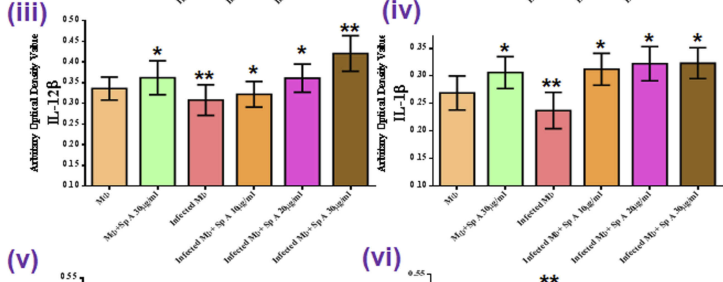

(v)

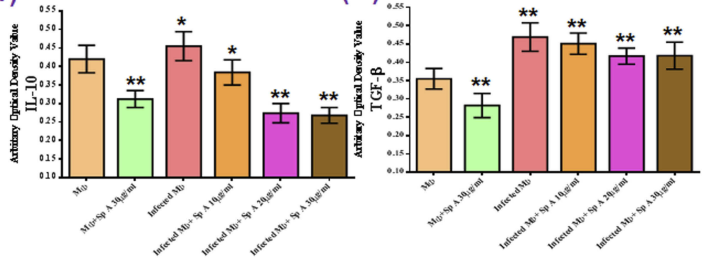

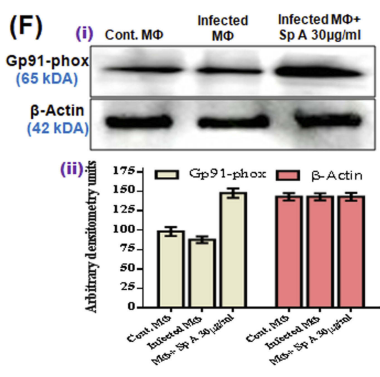
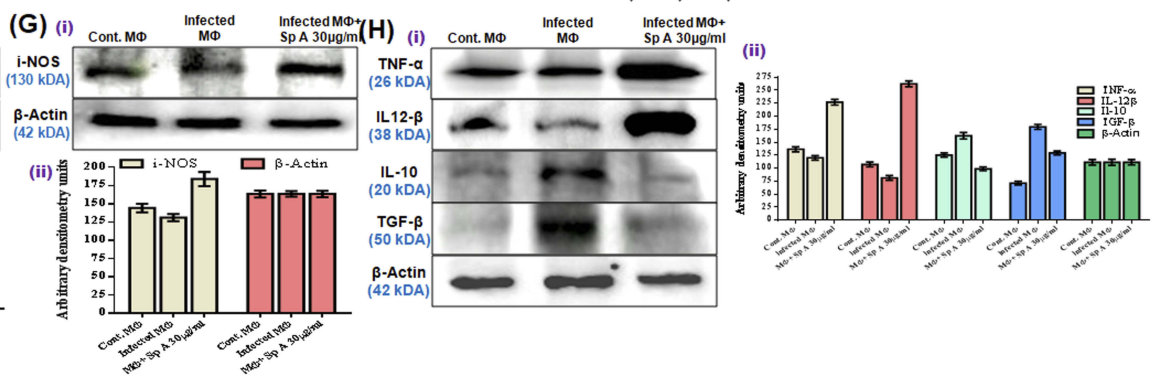

Figure 4 Elaboration of the anti-leishmanial activity of Spergulin-A. (A) Quantitative dose-dependent assessment of intracellular CFSE-stained antileishmanial activity of Spergulin-A by flow cytometry after 24 hrs treatment. Changes in $М \Phi$ population harboring Leishmania donovani parasites seem insignificant in respect to the decrease of the ultimate parasite count inside MФs (vi) reciprocal to the tagged CFSE fluorescence signaling (vii). (B) Confocal laser-scanning micrographs to evaluate the reduction in intracellular CFSE-stained L. donovani after 24 hrs of Spergulin-A treatment (magnification I20x). (C) FACS monitored the changes in ROS production in control, infected, and treated (30 $\mu \mathrm{g} / \mathrm{mL}$ Spergulin-A) MФs with H2DCFDA. (D) The changes in intracellular NO production were monitored by FACS with fluorescent probe DAF-2 DA. (E)

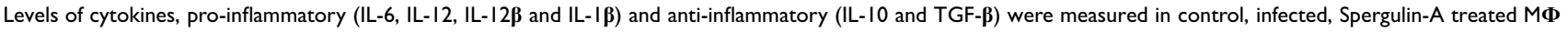
panels. (F, G, H) Changes in the expression of Gp9I-Phox, i-NOS and cytokines, namely pro-inflammatory TNF- $\alpha$, IL-I2 $\boldsymbol{\beta}$ and anti-inflammatory IL-I0 and TGF- $\boldsymbol{\beta}$ with $\boldsymbol{\beta}$ actin as loading control and densitometry analyses were provided after band normalization. Images are representative of three separate experiments, and all values are expressed as mean \pm SEM from triplicate assays from three independent experiments ( $P$-values $\leq 0.05(*)$ or $\leq 0.0 \mathrm{I}(* *)$ vs control). 
significant changes in number of parasitized MФs observed within the treatment panel (Figure 4A.vi) and what changes were the intensity denoted the parasite count (Figure 4A.vii). Thus, possibly Spergulin-A reduced the parasite by immunestimulating the host MФs.

Confocal micrographs depicted the reduction in parasite emitting green fluorescence with the increment of Spergulin-A doses. Moreover, most decreases were noticed when the parasitized MФs were treated with 30 $\mu \mathrm{g} / \mathrm{mL}$ of it (Figure 4B).

\section{Intracellular ROS and NO status due to infection and treatment}

The fluorescence intensity for H2DCFDA reciprocal to ROS production was found to be minimal for the infected panel (Figure 4C) and significantly higher in the treated panel (Figure 4C). The fluorescence intensity of DAF-2DA for NO was also found to be highest for the treated panel (Figure 4D) compared to the control and infected MФs (Figure 4D) (additional information can be obtained from Figure S7).

\section{Estimation of alteration of different cytokines and immunostimulators}

Levels of cytokines, both pro-inflammatory and anti-inflammatory were measured in control, infected, Spergulin-A treated MФ panels (Figure 4E.i-vi). As expected proinflammatory cytokine levels, namely IL-6, IL-12, IL-12 $\beta$ and IL-1 $\beta$ were decreased significantly due to $L$. donovani infection compared to control MФ (Figure 4E.i-iv). Reverse was observed for anti-inflammatory cytokines, $\mathrm{i}$. e., IL-10 and TGF- $\beta$ as their levels were significantly upregulated in the infection scenario (Figure 4E.v-vi). Spergulin-A exposure to the uninfected MФs was found to upregulated the pro-inflammatory cytokines in general and at the same time down-regulated the levels of antiinflammatory cytokines. Dose-dependent exposure of Spergulin-A $(10,20$ and $30 \mu \mathrm{g} / \mathrm{mL})$ towards the infected MФs increased the pro-inflammatory cytokines and also decreased the anti-inflammatory ones (Figure 4E.i-vi).

In Western blot analysis, it was observed that Gp91phox, the key component among the six subunits of NADPH oxidase liable for anti-microbial ROS production in MФs got up regulated in treated panel (Figure 4F.i-ii). Level of i-NOS which regulates anti-leishmanial NO production also increased with Spergulin-A treatment compared to control and infected MФs (Figure 4G.i-ii).
Leishmania inside the host cells can survive in cells via downregulating the pro-inflammatory cytokines while increasing the anti-inflammatory cytokine. Expression of pro-inflammatory TNF- $\alpha$ and IL- $12 \beta$ got down-regulated with infection and considerably up-regulated in treatment panel (Figure 4H.i-ii). Anti-inflammatory IL-10 and TGF$\beta$ expression were up-regulated in infected MФs compared to the control, and with the treatment of Spergulin-A (30 $\mu \mathrm{g} / \mathrm{mL})$ their appearance got normalized like that of control (TGF- $\beta$ ) or even less (IL-10) (Figure 4H.i-ii).

\section{Discussion}

Precisely an immune-suppressive ailment, VL inhabit and modulate the microbicidal function of the macrophages and create a microenvironment favoring parasite growth inside the visceral organs by modulating pro and anti-inflammatory cytokines and impairing ROS and NO release. ${ }^{6}$ The present in vitro study aimed to assess the immunostimulatory property of G. oppositifolius and isolation of a compound Spergulin-A which can reduce the intracellular parasites by immune-stimulation within a safe dose range for the host cells. Primary appraisal of an extract that can have an immunostimulatory effect was based upon the increased release of TNF- $\alpha$ and extracellular NO from treated MФs. It was observed that at an applied same dose (50 $\mu \mathrm{g} / \mathrm{mL}, 24 \mathrm{hrs}$ ) only the $\mathrm{n}-\mathrm{BuOH}$ fraction showed a considerable increase in TNF- $\alpha$ and extracellular NO production. The selection of TNF- $\alpha$ and extracellular NO as the potent immunostimulatory index in the present context is vital because endogenous TNF- $\alpha$ produced by infected macrophages can elicit the release of L-arginine-derived nitrogen intermediates detrimental for the intracellular parasites. ${ }^{9}$ The six n-BuOH sub-fractions were again verified for immune-stimulation, and fraction 4 emerged as the most promising one. The fraction was also considered to be safe for the MФs even at $50 \mu \mathrm{g} / \mathrm{mL}$ (81.5\% viability) having $\mathrm{CC}_{50}$ well above $100 \mu \mathrm{g} / \mathrm{mL}$.

Interested by the initial observations on elevated immunostimulation by the $\mathrm{n}-\mathrm{BuOH}$ sub-fraction 4 and based upon the previous inspection of the presence of triterpenoid saponins in this fraction ${ }^{24}$ a triterpenoid saponin Spergulin-A was isolated and purified following the well-established method (Figure 3A and Supplementary information). ${ }^{19,24}$

Evaluation of the anti-leishmanial property of Spergulin-A was the principal research interest after identification and isolation of it. The possible anti-leishmanial effect was first checked against the acellular forms of the parasite but without major success even at $100 \mu \mathrm{g} / \mathrm{mL}$ 
(Figure 3B). Therefore, if Spergulin-A has any leishmanicidal effect on the intracellular parasites that will possibly mediate by altering the microenvironment of the host МФs. After 24 hrs of incubation Spergulin-A $(30 \mu \mathrm{g} / \mathrm{mL})$ was found to be pretty useful in reducing the intracellular parasite count and when applied for a prolonged period of $72 \mathrm{hrs}$ reduction of intracellular Leishmania was significant in respect to both the infected МФs of corresponding time point and initial-parasitized MФs (Figure 3C and D). It is also of great significance that no considerable alteration in number of parasitized MФs was found in treatment panel while reduction of CFSE-stained internalized parasites was notable (Figure 4A). This specific observation strongly advocated in favor of immunostimulation by Spergulin-A which mediated parasite killing. For being leishmanicidal, Spergulin-A should be useful in enhancing the release of $\mathrm{NO}$ and $\mathrm{ROI}$, well recognized for their worth against Leishmania. ${ }^{6,25} \mathrm{NO}$ is especially critical for intracellular parasite clearance as it was reported that mice with impaired inducible nitric oxide synthase (i-NOS) and thus restricted production and release of $\mathrm{NO}$ are incapable of Leishmania control even for isolated macrophages in vitro. ${ }^{26}$ At the dose of $30 \mu \mathrm{g} / \mathrm{mL}$, Spergulin-A showed enhanced production of intracellular $\mathrm{NO}$ and ROI (Figure 4C and D) which was found to be directly reciprocal to the reduction of intracellular parasites and signified their connection. In the Western blot analysis also increment in i-NOS production (Figure 4G) was noticed in Spergulin-A treated parasitized MФs in amendable enhanced NO production and parasite control. The same interpretation is also pertinent for an increase of Gp91phox, a subunit of the NADPH oxidase and enhancement of ROI (Figure 4F and C) in Spergulin-A mediated intracellular parasite killing. It was previously established that intracellular leishmanial killing proceeds by NO production from arginine by i-NOS, and superoxide $\left(\mathrm{O}^{-}\right)$generated by the NADPH oxidase. ${ }^{27}$ Several Leishmania species induce immunosuppressive TGF- $\beta$ production, and diminution of TGF- $\beta$ secretion is in direct correlation with enhanced i-NOS production ${ }^{6}$ and can lead to internalized parasite removal as found with Spergulin-A treatment. TGF- $\beta$ also found to increase the VL progression and averts disease cure in murine models. ${ }^{27}$ IL-10 is another anti-inflammatory cytokine which makes macrophages indifferent to various activation signals and thus causes impairment of intracellular parasite killing also by down-regulating the production of TNF- $\alpha$ and NO. ${ }^{28} \mathrm{IL}-10$ production increased in infected macrophages in vitro, apparently via interaction with the $\mathrm{Fc}$ receptor ${ }^{29}$ and which down-regulated with Spergulin-A treatment (Figure 4E and $\mathrm{H}$ ) in connection with parasite reduction. Parasite infection is responsible for the suppression of macrophage microbicidal activity that relies upon NO, ROI and cytokines like IL-1, IL-12 $\beta$, and TNF- $\alpha^{30}$ as with infection the levels of TNF- $\alpha$ IL- $12 \beta$ got down-regulated (Figure 4E), but with the application of Spergulin-A, these cytokines significantly elevated which signifies their role in intracellular Leishmania parasite control.

\section{Conclusion}

The inconsistency of direct leishmanicidal effect of G. oppositifolius and Spergulin-A isolated from it against promastigotes and axenic amastigotes, on the one hand, and the proved efficacy of them against intracellular parasites was explained by emphasizing host $\mathrm{M} \Phi$ immunostimulation as elaborated precisely in the present study. Bio-guided fractionation was employed to isolate and identify Spergulin-A as the immunostimulant, and its anti-leishmanial property was evaluated at a dose best suited for the research and found to be safe against the host cells assessed in vitro in RAW 264.7 MФs infected with a virulent strain of $L$. donovani.

\section{Acknowledgment}

Sincere thanks are given to Science and Engineering Research Board, Govt. of India (Grant No. PDF/2016/001437 and EMR/ 2015/001674) for financial assistance. The manuscript has been checked critically by the full version of the Grammarly software and corrected by Dr. Basudeb Achari, ex-scientist of CSIR-Indian Institute of Chemical Biology.

\section{Disclosure}

The authors report no conflicts of interest in this work.

\section{References}

1. Tiuman TS, Santos AO, Ueda-Nakamura T, Filho BP, Nakamura CV. Recent advances in leishmaniasis treatment. Int J Infect Dis. 2011;15: e525-e532. doi:10.1016/j.ijid.2011.03.021

2. Alvar J, Ve'lez ID, Bern C, et al. Leishmaniasis worldwide and global estimates of its incidence. PLoS One. 2012;7:e35671. doi:10.1371/ journal.pone.0035671

3. Banerjee S, Bose D, Chatterjee N, et al. Attenuated Leishmania induce pro-inflammatory mediators and influence leishmanicidal activity by p38 MAPK dependent phagosome maturation in Leishmania donovani co-infected macrophages. Sci Rep. 2016;6:22335. doi:10.1038/ srep22335

4. Freitas EO, Leoratti FMS, Freire-de-Lima CG, Morrot A, Feijó DF. The contribution of immune evasive mechanisms to parasite persistence in visceral leishmaniasis. Front Immunol. 2016;7:153. doi:10.3389/fimmu.2016.00153 
5. Bhardwaj S, Srivastava N, Sudan R, Saha B. Leishmania interferes with host cell signaling to devise a survival strategy. J Biomed Biotechnol. 2010;2010:109189. doi:10.1155/2010/109189

6. Olivier M, Gregory DJ, Forget G. Subversion mechanisms by which Leishmania parasites can escape the host immune response: a signaling point of view. Clin Microbiol Rev. 2005;18:293-305. doi:10.1128/CMR.18.2.293-305.2005

7. Goto H, Lindoso JAL. Immunity and immunosuppression in experimental visceral leishmaniasis. Braz J Med Biol Res. 2004;37:615623. doi:10.1590/S0100-879X2004000400020

8. Islamuddin M, Chouhan G, Want MY, Ozbak HA, Hemeg HA, Afrin F. Immunotherapeutic potential of eugenol emulsion in experimental visceral leishmaniasis. PLoS Negl Trop Dis. 2016;10:e0005011. doi:10.1371/journal.pntd.0005011

9. Maran N, Gomes PS, Freire-de-Lima L, Freitas EO, Freire-de-Lima CG, Morrot A. Host resistance to visceral leishmaniasis: prevalence and prevention. Expert Rev Anti Infect Ther. 2016;14:435-442. doi:10.1586/14787210.2016.1160779

10. Flora R, Aghazadeh-Dibavar S, Bandyopadhyay M, Dasgupta S. Immunosuppression during Leishmania donovani infection: a potential target for the development of therapy. Ann Parasitol. 2014;60:239-245.

11. Haidaris CG, Bonventre PF. Efficacy of combined immunostimulation and chemotherapy in experimental visceral Leishmaniasis. Am J Trop Med Hyg. 1983;32:286-295. doi:10.4269/ajtmh.1983.32.512

12. Mukherjee N, Mukherjee S, Saini P, Roy P, Sinha Babu SP. Phenolics and terpenoids; the promising new search for anthelmintics: a critical review. Mini Rev Med Chem. 2016;16:1415-1441. doi:10.2174/ 1389557516666151120121036

13. Inngjerdingen KT, Kiyohara H, Matsumoto T, et al. An immunomodulating pectic polymer from Glinus oppositifolius. Phytochemistry. 2007;68:1046-1058. doi:10.1016/j.phytochem.2007.01.011

14. Sahakitpichan P, Disadee W, Ruchirawat S. Kanchanapoom T. L(-)-(N-trans-cinnamoyl)-arginine, an acylamino acid from Glinus oppositifolius (L.) Aug. DC. Molecules. 2010;15:6186-6192. doi: 10.3390/molecules 15096186

15. Traore F, Faure R, Ollivier E, et al. Structure and antiprotozoal activity of triterpenoid saponins from Glinus oppositifolius. Planta Med. 2000;66:368-371. doi:10.1055/s-2000-8551

16. Sahu SK, Das D, Tripathy NK, Dinda SC, Sundeep Kumar HK. Evaluation of hypoglycemic activity of Mollugo pentaphylla and Glinus oppositifolius (L). Rasayan J Chem. 2012;5:57-62.

17. Kumar D, Shah V, Ghosh R, Pal BC. A new triterpenoid saponins from Glinus oppositifolius with a-glucosidase inhibitory activity. Nat Prod Res. 2013;27:624-629. doi:10.1080/14786419.2012.686907
18. Kaur H, Thakur A, Kaur S. Immunoprophylactic potential of a cocktail of three low molecular weight antigens of leishmania donovani along with various adjuvants against experimental visceral leishmaniasis. Iran J Parasitol. 2018;13:11-23.

19. Kumar D, Mallick S, Vedasiromoni JR, Pal BC. Anti-leukemic activity of Dillenia indica L. fruit extract and quantification of betulinic acid by HPLC. Phytomedicine. 2010;17:431-435. doi:10.1016/j. phymed.2010.04.005

20. Saar Y, Ransford A, Waldman E, et al. Characterization of developmentally-regulated activities in axenic amastigotes of Leishmania donovani. Mol Biochem Parasitol. 1998;95:9-20. doi:10.1016/s01666851(98)00096-6

21. Chatterjee N, Das S, Bose D, et al. Exploring the anti-inflammatory activity of a novel 2-phenylquinazoline analog with protection against inflammatory injury. Toxicol Appl Pharmacol. 2012;264:182-191. doi:10.1016/j.taap.2012.07.032

22. Mosmann T. Rapid colorimetric assay for cellular growth and survival: application to proliferation and cytotoxicity assays. J Immunol Methods. 1983;65:55-63. doi:10.1016/0022-1759(83)90303-4

23. Sikdar Y, Modak R, Bose D, et al. Doubly chloro bridged dimeric copper(II) complex: magneto-structural correlation and anticancer activity. Dalton Trans. 2015;44:8876. doi:10.1039/C5DT00752F

24. Sahu NP, Koike K, Banerjee S, Achari B, Nikaido T. Triterpenoid saponins from Mollugo spergula. Phytochemistry. 2001;58:11771182. doi:10.1016/s0031-9422(01)00346-6

25. Matte C, Maion G, Mourad W, Olivier M. Leishmania donovaniinduced macrophages cyclooxygenase-2 and prostaglandin E2 synthesis. Parasite Immunol. 2001;23:177-184. doi:10.1046/j.13653024.2001.00372.x

26. Wei XQ, Charles IG, Smith A, et al. Altered immune responses in mice lacking inducible nitric oxide synthase. Nature. 1995;375:408411. doi:10.1038/375196b0

27. Wilson ME, Jeronimo SMB, Pearson RD. Immunopathogenesis of infection with the visceralizing Leishmania species. Microb Pathogenesis. 2005;38:147-160. doi:10.1016/j.micpath.2004.11.002

28. Nylen S, Sacks D. Interleukin-10 and the pathogenesis of human visceral leishmaniasis. Trends Immunol. 2007;28:378-384. doi:10.1016/j. it.2007.07.004

29. Sutterwala FS, Noel GJ, Salgame P, Mosser DM. Reversal of proinflammatory responses by ligating the macrophage Fcgamma receptor type I. J Exp Med. 1998;188:217-222. doi:10.1084/jem.188.1.217

30. Kane MM, Mosser DM. Leishmania parasites and their ploys to disrupt macrophage activation. Curr Opin Hematol. 2000;7:26-31. doi:10.1097/00062752-200001000-00006
Infection and Drug Resistance

\section{Publish your work in this journal}

Infection and Drug Resistance is an international, peer-reviewed openaccess journal that focuses on the optimal treatment of infection (bacterial, fungal and viral) and the development and institution of preventive strategies to minimize the development and spread of resistance. The journal is specifically concerned with the epidemiology of antibiotic resistance and the mechanisms of resistance development and diffusion in both hospitals and the community. The manuscript management system is completely online and includes a very quick and fair peerreview system, which is all easy to use. Visit http://www.dovepress.com/ testimonials.php to read real quotes from published authors. 